\title{
A comparison of intravaginal misoprostol with sublingual misoprostol for second trimester medical termination of pregnancy
}

\author{
Ankita Pandey ${ }^{1 *}$, Sarmila Kundu ${ }^{1}$, Prasad Yeshwant Deshmukh ${ }^{2}$
}

\begin{abstract}
${ }^{1}$ Department of Obstetrics \& Gynaecology, Nilratan Sircar Medical College \& Hospital, Kolkata, West Bengal, India
${ }^{2}$ Department of Obstetrics \& Gynaecology, LTMMC \& GH, Sion, Mumbai, Maharashtra, India
\end{abstract}

Received: 03 February 2015

Revised: 20 February 2015

Accepted: 01 March 2015

\author{
*Correspondence: \\ Dr. Ankita Pandey, \\ E-mail: sonamnrs86@gmail.com
}

Copyright: () the author(s), publisher and licensee Medip Academy. This is an open-access article distributed under the terms of the Creative Commons Attribution Non-Commercial License, which permits unrestricted non-commercial use, distribution, and reproduction in any medium, provided the original work is properly cited.

\begin{abstract}
Background: Second trimester abortions generally account for less number of patients as compared to first trimester abortions as patients generally come earlier as soon as pregnancy is recognized but now days due to advent of USG many cases of fetal anomaly are detected earlier accounting for increasing number of cases of second trimester.

Methods: Present study was conducted among patients with pregnancy between 13-20 weeks of period of gestation (to be randomly assigned) after getting approval from institutional ethics committee and informed consent from the patient. Participants were randomly allocated to receive $400 \mu \mathrm{g}$ of misoprostol either sublingually or intravaginally every six hours for a maximum of 5 doses. The blood pressure, pulse rate $\&$ temperature and side effects monitored every $3 \mathrm{hrs}$. If women in either group failed to abort after 48 hours of initiation of treatment termed as failure. In cases of failure they were given additional doses of sublingual misoprostol till abortion occurred. Primary outcome variable compared was success rate at 48 hours. Secondary outcome variables compared were bleeding patterns, completeness of abortion, induction abortion interval and any side effects.

Results: It has been found that vaginal misoprostol 400 micro gm achieved a success rate to $100 \%$ in 48 hours, while the success rate was $93.33 \%$ with the sublingual route. $(\mathrm{P}=0.4915, \mathrm{NS})$.

Conclusions: Thus from our limited study population, we conclude that there is no significant difference in efficacy and complications between the two routes, although a larger cohort is required to get more dependable result.
\end{abstract}

Keywords: Intravaginal misoprostol, Sublingual misoprostol, Pregnancy \& gestation, Larger cohort

\section{INTRODUCTION}

Safe and legal abortion is considered to be a key intervention for improving women's health and quality of life. ${ }^{1}$ In our country a significant number of women practice contraception but Medical Termination of Pregnancy (MTP) is also used to control family size and birth spacing. ${ }^{2}$ As a result, an overwhelming proportion of induced abortions (6.7 million annually-an indirect estimate) take place in India ${ }^{3}$ and elective termination of pregnancy is considered as a commonly performed gyanecological procedure. ${ }^{4}$
Second trimester abortions constitute $10-15 \%$ of all induced abortions worldwide, but are related to twothirds of major abortion related complications. ${ }^{5}$ During the last decade, medical methods for second trimester induced abortions have has considerably improved and became safe and more accessible.

Although several methods have been tried over the years with varying success, the ideal method for mid-trimester abortion remains elusive, as indicated by the constant search for new methods. ${ }^{5-9}$ Ethacridine lactate has a long history of use in our country and is recommended for use 
for mid-trimester MTP. ${ }^{7}$ However, its use has certain disadvantages such as a longer instillation abortion interval, a higher failure rate and more chances of incomplete abortion. ${ }^{8,9}$ Prostaglandin analogue is commonly used for termination of pregnancy in the second trimester.

Misoprostol is the prostaglandin analogue commonly used, as it is cheap and stable at room temperature. It has been shown to be effective for second trimester termination of pregnancy. ${ }^{6,8,9}$ Various studies showed that medical abortion is feasible in the first trimester by a combination of mifepristone and repeated dose of misoprostol. Study report also shows that misoprostol in combination with mifepristone is an effective regimen for termination of second trimester abortion up to 20 weeks. ${ }^{10-12}$ Mifepristone is, however, expensive and not approved in most countries of the world. Therefore, it is very important to develop a cost-effective regimen of medical abortion without mifepristone so that women particularly of developing countries can be benefited from its advantages.

In this regard repeated doses of misoprostol have been in use widely. Misoprostol, now a days, is the prostaglandin of choice throughout the world as it has selective mode of action as an E1 prostaglandin and has low rate of sideeffects. Additional benefits of misoprostol are - it is cheap, easily available, stable at room temperature and easy to use. Initially, misoprostol was used orally for medical abortion. However, the use of vaginal misoprostol is becoming a common practice for both medical abortion and cervical priming for other indications. Many clinical trials have found that vaginal administration is more effective than oral administration. ${ }^{13}$ This was supported by pharmacokinetic study showing that systemic bioavailability after vaginal administration of misoprostol was three times higher than that after oral administration. ${ }^{13}$ However, there has been suggestive evidence showing that absorption through vaginal route is inconsistent and it is not uncommon to find the undissolved misoprostol tablets several hours after vaginal administration. Subsequently a new route of giving misoprostol by sublingual administration has been developed. ${ }^{14}$ The sublingual mucosa, being very vascular, serves the purpose of better absorption. Sublingual application also avoids the first pass effect through the liver. The misoprostol tablets, when placed under the tongue, dissolve within 10-15 min. Preliminary data showed that this is a promising route for administration of misoprostol for medical abortion.

The use of sublingual misoprostol for medical abortion has been explored. A pharmocokinetic study has demonstrated that sublingual administration could achieve the peak concentration in the shortest time and has the highest bioavailability. ${ }^{15}$

Different routes may be used for administration of misoprostol for second trimester abortion but there is no commonly approved opinion indicating the most effective route. Many studies showed that oral route is the least effective, but between vaginal and sublingual route the opinion still varies regarding which one is better.

Analysing earlier information, we realize that it is important to determine the efficacy, outcome and adverse effects of second trimester medical abortion by intravaginal misoprostol and sublingual misoprostol.

Hypothesis of our study is that sublingual misoprostol is a better alternative to pervaginal misoprostol as a means of second trimester medical termination of pregnancy.

\section{METHODS}

\section{Study area}

Patients attending gynaecology OPD \& family planning clinic in the dept. of obstetrics \& gynaecology at NRS medical college \& hospital, Kolkata.

\section{Study population}

Women attending the hospital for voluntary mid-trimester MTP i.e. 13-20 weeks of pregnancy.

\section{Inclusion criteria}

- Women were included in the trial if termination of pregnancy could be made in accordance with the MTP act if India.

- Healthy patients with $\mathrm{Hb}>10 \mathrm{~g} / \mathrm{d} 1$.

- Patients with period of gestation 13 weeks-20 weeks.

- Patients not allergic to prostaglandins.

\section{Exclusion criteria}

- Patients with period of gestation <13 weeks or more than 20 weeks gestation.

- Patient with low Hb levels (<10 g/dl)

- Scarred uterus.

- Patients with unstable cardiopulmonary status.

- Patients on anticoagulants.

- Patients with hypersensitivity to prostaglandins.

- $\quad$ Patients giving history of bleeding per vagina. 


\section{Study period}

April 2012 to March 2013.

\section{Study tools}

\section{i. Clinical examination report \\ ii. Drugs - misoprostol \\ iii. Ultrasonography}

\section{Sample size}

60 women carrying singleton pregnancy were selected for the study.

\section{Sample design}

Case selection was done by taking consecutive 60 women \& randomly assigning them to either intravaginal misoprostol or sublingual misoprostol in 1:1 ratio.

\section{Study design}

Present study was conducted among patients with pregnancy between 13-20 weeks of period of gestation (to be randomly assigned) after getting approval from institutional ethics committee and informed consent from the patient.

a) Participants were randomly allocated to receive 400 $\mu \mathrm{g}$ of misoprostol either sublingually or intravaginally every six hours for a maximum of 5 doses.

The blood pressure, pulse rate \& temperature and side effects monitored every 3 hours.

If women in either group failed to abort after 48 hours of initiation of treatment termed as failure. In cases of failure they were given additional doses of sublingual misoprostol till abortion occurred.

\section{Primary outcome variables}

Success rate at 48 hours defined as abortion occurring without the need for further prostaglandin analogue. Failure in both groups was defined as failed expulsion of fetus at 48 hours or occurrence of systemic adverse sign $\&$ symptoms severe enough to withhold any further doses of misoprostol.

\section{Secondary outcome variables}

i. Bleeding pattern following treatment in both groups - Patients requiring blood transfusion, acceptability.

ii. Completeness of abortion - expulsion of both placenta and fetus by visual inspection \& in cases if any symptoms like excessive or persistent bleeding per vagina developed USG was done and in any case of suspicion of incomplete abortion evacuation of retained products by surgical method was done.

iii. Induction - abortion interval

iv. Side effects

\section{Parameters to be studied}

i) Before treatment

- Clinical history

- Baseline Hb levels

- Maternal vital signs (Pulse rate, BP, general condition, weight, height)

- USG - to confirm period of gestation and exclude other pelvic pathology.

- Patients to be randomly selected

ii) Complete evacuation rate

iii) $\mathrm{Hb} \%$ levels in both groups

iv) Safety evaluation by measuring occurrence of adverse effects in both groups

- Maternal subjective complains

- Lower abdominal pain

- Fever $>38^{\circ} \mathrm{C}$

- Diarrhoea

\section{Plan for analysis of data}

Statistical analysis to be done from the outcome. All variable to be calculated by $\pm 2 \mathrm{SD}$. Collected data were analysed and statistical test was done with the help of Microsoft excel and Quickcalcs software.

Test for the statistical significance was applied by using Chi square test and Fischer's exact test for analyzing the differences between the two groups $(\mathrm{P}<0.05$ was considered significant).

\section{RESULTS}

Maximum No. of patients were in the 20-25 years group. The two groups were comparable with respect to age distribution.

Table 1: Age distribution in two groups.

\begin{tabular}{|c|c|c|c|}
\hline Age & $\begin{array}{l}\text { Sublingual } \\
\mathrm{n}=\mathbf{3 0}\end{array}$ & $\begin{array}{l}\text { Pervaginal } \\
\mathbf{n}=\mathbf{3 0}\end{array}$ & P value \\
\hline $20-25$ & 18 & 21 & \multirow{4}{*}{$0.886(\mathrm{NS})$} \\
\hline $25-30$ & 9 & 6 & \\
\hline $30-35$ & 3 & 3 & \\
\hline Mean & $24 \pm 3.6$ years & $23 \pm 3.2$ years & \\
\hline
\end{tabular}

Maximum No. of the patients had gestational age in the 15-18 weeks in the sublingual group and 13-15 weeks in the pervaginal group. The two groups were however comparable with respect to gestational age distribution. 
Table 2: Distribution of the women of two groups according to gestational age.

\begin{tabular}{|c|c|c|c|}
\hline Weeks & $\begin{array}{l}\text { Sublingual } \\
n=30\end{array}$ & $\begin{array}{l}\text { Pervaginal } \\
n=30\end{array}$ & P value \\
\hline $13-15$ & 9 & 12 & \multirow{4}{*}{$0.5173(\mathrm{NS})$} \\
\hline $15-18$ & 12 & 10 & \\
\hline $18-20$ & 9 & 8 & \\
\hline $\begin{array}{l}\text { Mean gest } \\
\text { age }\end{array}$ & $16.4 \pm 2.4$ & $16 \pm 2.4$ & \\
\hline
\end{tabular}

Maximum No. of patients were multipara in both groups.

Table 3: Parity distribution in two groups.

\begin{tabular}{|llll|}
\hline Parity & $\begin{array}{l}\text { Sublingual } \\
(\mathrm{n}=30)\end{array}$ & $\begin{array}{l}\text { Pervaginal } \\
(\mathrm{n}=30)\end{array}$ & P value \\
\cline { 1 - 4 } Nulliparous & $6(20 \%)$ & $9(30 \%)$ & \multirow{2}{*}{$0.5520(\mathrm{NS})$} \\
\hline Multiparous & $24(80 \%)$ & $21(70 \%)$ & \\
\hline
\end{tabular}

Most common indication for termination of pregnancy in both groups was failure of contraception about $80 \%$ in the sublingual group and $73 \%$ in the pervaginal group.

Table 4: Primary indication for termination.

\begin{tabular}{|lll|}
\hline Indication & $\begin{array}{l}\text { Sublingual } \\
(\mathrm{n}=30)\end{array}$ & $\begin{array}{l}\text { Pervaginal } \\
(\mathrm{n}=28)\end{array}$ \\
\hline Failure of contraception & $24(80 \%)$ & $22(73 \%)$ \\
\hline Social indications & 0 & $2(6 \%)$ \\
\hline Fetal anomalies & $3(10 \%)$ & $4(13 \%)$ \\
\hline Maternal indication & $3(10 \%)$ & $2(6 \%)$ \\
\hline
\end{tabular}

Most of the patients in the sublingual group aborted within 12-24 hours while in the pervaginal group within $12 \mathrm{hrs}$. There were two failures in the sublingual group although the mean induction - abortion interval in the two groups were comparable with insignificant $\mathrm{P}$ value. Within 24 hours $90 \%$ of the patients in the vaginal group aborted while in the sublingual group $80 \%$ of the patient aborted.

Table 5: Abortion interval in two groups.

\begin{tabular}{|c|c|c|c|}
\hline Time (hours) & $\begin{array}{l}\text { Sublingual } \\
(\mathrm{n}=\mathbf{3 0})\end{array}$ & $\begin{array}{l}\text { Pervaginal } \\
(\mathbf{n}=\mathbf{3 0})\end{array}$ & P value \\
\hline$<12$ hours & 9 & 18 & \multirow{6}{*}{$0.5662(\mathrm{NS})$} \\
\hline 12-24 hours & 15 & 9 & \\
\hline 24-36 hours & 3 & 3 & \\
\hline 36-48 hours & 1 & 0 & \\
\hline$>48$ hours & 2 & 0 & \\
\hline Mean (hours) & $\begin{array}{l}15.4 \pm 8.08 \\
\text { hours }\end{array}$ & $\begin{array}{l}14.4 \pm 5.3 \\
\text { hours }\end{array}$ & \\
\hline
\end{tabular}

In the sublingual group both failures were in the 15-18 weeks group while in the pervaginal group there was $100 \%$ success rate in all the three groups $\mathrm{P}=0.4915$ (NS).
Table 6: Comparison of gestational age and success rate in the two groups.

\begin{tabular}{|ll|l|}
\hline Gest age & $\begin{array}{l}\text { Sublingual } \\
(\mathrm{n}=30)\end{array}$ & $\begin{array}{l}\text { Pervaginal } \\
(\mathrm{n}=30)\end{array}$ \\
\hline $13-15$ weeks & $9 / 9(100 \%)$ & $12 / 12(100 \%)$ \\
\hline $15-18$ weeks & $10 / 12(83.3 \%)$ & $9 / 9(100 \%)$ \\
\hline $18-20$ weeks & $9 / 9(100 \%)$ & $9 / 9(100 \%)$ \\
\hline Overall success rate & $28 / 30(93.3 \%)$ & $30 / 30(100 \%)$ \\
\hline
\end{tabular}

In the sublingual group 7 in 28 cases had incomplete evacuation while in the pervaginal group 9 in 30 cases had incomplete evacuation. All cases of incomplete evacuation were followed by check curettage.

Table 7: Completeness of abortion in two groups.

\begin{tabular}{|llll|} 
& $\begin{array}{l}\text { Sublingual } \\
(\mathbf{n}=28)\end{array}$ & $\begin{array}{l}\text { Pervaginal } \\
(\mathbf{n}=30)\end{array}$ & P value \\
\cline { 1 - 2 } Complete & $21 / 28(75 \%)$ & $21 / 30(70 \%)$ & \multirow{2}{*}{$0.7725(\mathrm{NS})$} \\
\cline { 1 - 3 } Incomplete & $7 / 28(25 \%)$ & $9 / 30(30 \%)$ & \\
\hline
\end{tabular}

The deficit in mean $\mathrm{Hb} \%$ in the sublingual group between day 1 and day 15 was $0.6 \%$.

Table 8: Comparison of pre and post $\mathrm{Hb} \%$ deficit in sublingual group.

\begin{tabular}{|c|c|c|c|}
\hline $\mathrm{Hb} \%$ & Day $1(n=30)$ & Day $15(n=28)$ & Deficit \\
\hline $8-10 \%$ & 0 & 9 & \multirow{4}{*}{$0.6 \mathrm{mg} / \mathrm{dl}$} \\
\hline $10-12 \%$ & 24 & 16 & \\
\hline $12-14 \%$ & 6 & 3 & \\
\hline Mean & $11.2 \pm 0.98 \%$ & $10.6 \pm 0.93 \%$ & \\
\hline
\end{tabular}

The mean $\mathrm{Hb} \%$ deficit in the pervaginal group was 0.8 $\mathrm{g} \%$.

Table 9: Pre and post $\mathrm{Hb} \%$ deficit in pervaginal group.

\begin{tabular}{|llll|}
\hline Hb \% & Day 1 & Day 15 & Deficit \\
\hline $8-10 \%$ & 0 & 6 & \\
\hline $10-12 \%$ & 19 & 18 & \\
\hline $12-14 \%$ & 11 & 6 & \\
\hline Mean & $11.6 \pm 1.04$ & $10.8 \pm 0.95$ & $0.8 \mathrm{mg} / \mathrm{dl}$ \\
\hline
\end{tabular}

Table 10: Comparison of side effects in two groups.

\begin{tabular}{|lll|} 
Side effects & $\begin{array}{l}\text { Sublingual } \\
(\mathrm{n}=28)\end{array}$ & $\begin{array}{l}\text { Pervaginal } \\
(\mathrm{n}=30)\end{array}$ \\
\hline Nausea & $9(30 \%)$ & $6(20 \%)$ \\
\hline Vomiting & $6(20 \%)$ & $3(10 \%)$ \\
\hline Diarrhoea & $3(10 \%)$ & $9(30 \%)$ \\
\hline Fever $\left(>100.4^{\circ} \mathrm{F}\right)$ & $3(10 \%)$ & $12(40 \%)$ \\
\hline
\end{tabular}

The most common side effect seen in the sublingual group was nausea whereas the most common adverse effect seen in the pervaginal group was fever. All the side 
effects were comparable in both groups except incidence of fever which was high in the pervaginal group.

Table 11: Preference of the route of administration in the two groups.

\begin{tabular}{|lll|}
\hline & $\begin{array}{l}\text { Sublingual } \\
(\mathbf{n = 3 0})\end{array}$ & $\begin{array}{l}\text { Pervaginal } \\
(\mathbf{n}=30)\end{array}$ \\
\hline Preferred the route & 26 & 18 \\
\hline Did not prefer & 4 & 12 \\
\hline
\end{tabular}

26 women out of 30 in the sublingual group preferred the route as they found it more convenient and had less discomfort. 4 of them did not like the route as they did not like the taste of the drug.

In the pervaginal group 12 out of 30 women did not prefer the route due to discomfort while 18 preferred the route as they thought it to be more effective.

\section{DISCUSSION}

Second trimester abortions constitute $10-15 \%$ of all induced abortions worldwide, but are related to twothirds of major abortion related complications. There is no consensus opinion concerning the most ideal method for termination of second trimester pregnancies. While determining the most appropriate method, cheapness, reduced number of doses and tolerability of its complications are important criteria.

In this study, the two comparing groups are:

Group A: receiving sublingual misoprostol 400 micro gram 6 hourly (upto maximum 5 doses)

Group B: receiving pervaginal misoprostol 400 micro gram 6 hourly (upto maximum 5 doses)

The mean gestational age was $16 \pm 2.4$ weeks in the sublingual group and $16 \pm 2.4$ weeks in the pervaginal group (Table 2) which corresponds to study by Tang et al. $^{16}$ in which the mean gestational age were $15.4 \pm 2$ weeks and $15.2 \pm 1.9$ weeks respectively.

The clinical efficacy of pervaginal misoprostol appeared to be slightly superior to sublingual group as shown by success rate at 24 hours which was $90 \%$ in the pervaginal group as compared to $80 \%$ in sublingual. This corresponds to study done by Tang et al. ${ }^{16}$ which also shows success rates of $86 \%$ and $72 \%$ respectively. Moreover the success rate at the end of 48 hours was also higher in the pervaginal group $(100 \%)$ as compared to sublingual (93.3\%) (Table 6). This is in accordance to study by Tang et al. ${ }^{16}$ in which success rate was $91 \%$ for sublingual group and $95 \%$ for pervaginal group. Also Bhattacharjee et al. ${ }^{17}$ found success rate of $79 \%$ and $82 \%$ respectively in the sublingual and pervaginal groups and was statistically insignificant. Tanha et al. ${ }^{18}$ found the success rate of $61 \%$ in the pervaginal group and $70 \%$ in the sublingual group which was statistically insignificant.
The mean induction - abortion interval was 15.4 hours in sublingual and 14.4 hours in the pervaginal group and was statistically insignificant. This result corresponds with earlier study done by Tang et al. ${ }^{16}$ where in the sublingual group the interval was 13.2 hours and in the pervaginal group was 12 hours and the two values were also statistically insignificant. Bhattacharjee et al. ${ }^{17}$ found induction - abortion interval to be 14.1 and 14.5 hours in the sublingual and pervaginal groups respectively and was statistically insignificant.

In the sublingual group $75 \%$ of the patients had complete abortion as compared to pervaginal group in which $70 \%$ of the patients had (Table 7). This is similar to study by Tang et al. ${ }^{16}$ and Tanha et al. ${ }^{18}$

The side effects were comparable in both the groups, only significant difference being fever which was significantly higher in the pervaginal group (Table 10). This corresponds to study by Tang et al. ${ }^{16}$ and by Bhattacharjee et al. ${ }^{17}$

The fall in $\mathrm{Hb} \%$ two groups was comparable and the deficit was statistically insignificant.

Regarding acceptability, the sublingual group was the preferred route of administration (Table 11). These findings agreed with previous studies which showed women like to take misoprostol by oral route as it was more comfortable and provided more privacy. ${ }^{16}$

In this study we used repeated doses of misoprostol (400 micro gm) in two routes for mid trimester abortion.

It has been found that vaginal misoprostol 400 micro gm achieved a success rate to $100 \%$ in 48 hours, while the success rate was $93.33 \%$ with the sublingual route $(\mathrm{P}=$ $0.4915, \mathrm{NS})$.

The induction - abortion interval was $14.4 \pm 5.3$ hours in vaginal route and $15.4 \pm 8.08$ hours with the sublingual route. ( $\mathrm{P}=0.5662$, NS). So we found that both success rate and induction-abortion interval were comparable for the two routes of administration. Thus both sublingual and vaginal routes are effective for medical abortion in Second trimester.

However more women aborted in 24 hours if vaginal misoprostol was used that is $90 \%$ in the vaginal as compared to $80 \%$ in the sublingual group ( $\mathrm{P}=0.4716$, NS).

The side effects were similar in both groups except the occurrence of fever which was significantly higher in the vaginal group $(\mathrm{P}=0.0159, \mathrm{~S})$. No serious complication was noted in any of the groups.

Regarding acceptability it appeared that sublingual was a more preferable way of administration of the drug.

Thus from our limited study population, we conclude that there is no significant difference in efficacy and 
complications between the two routes, although a larger cohort is required to get more dependable result.

Funding: No funding sources

Conflict of interest: None declared

Ethical approval: The study was approved by the institutional ethics committee

\section{REFERENCES}

1. Dhillon BS, Chandhiok N, Kambo I, Saxena NC. Induced abortion and concurrent adoption of contraception in rural areas of India (an ICMR task force study). Indian J Med Sci. 2004;58:478-84.

2. Tejal P, Bakul A. 17 year review of voluntary termination of pregnancy (MTP). J Obstet Gynaecol India. 2006;56:522-8.

3. Santhya KG, Verma S. Induced abortion: the current scenario in India. Regional Health Forum WHO South-East Asia Region. 2004;8(2):1-14.

4. Goyel BK, Singh G. Midtrimester MTP using endocervical PGE2 gel and serial intramuscular carboprost. Med J Armed Forces India. 2000;56:379.

5. Drey EA, Foster DG, Jackson RA, Lee SJ, Cardenas LH, Darney PD. Risk factors associated with presenting for abortions in second trimester. Obstet Gynaecol. 2006;107(1):128-35.

6. Goldberg AB, Greenberg MB, Darney PD. Misoprostol and Pregnancy. N Engl J Med. 2001;344:38-47.

7. FOGSI ICOG Consensus Guidelines. Medical termination of pregnancy. In: FOGSI, eds. Newsletter of Indian College of Obstetricians and Gynaecologists. Mumbai: FOGSI; 2005: 36.

8. Chaudhari S, Mitra SN, Chadhari N, Chattopadhya D, Banerjee D. A Comparison of intravaginal misoprostol with extra amniotic ethacridine lactate for second trimester MTP. Obstet Gynaecol India. 2006;56:518-21.

9. Lalitkumar S, Bygdeman M, Genmzell-Danielsson K. Mid trimester induced abortion a review. Hum Reprod Update. 2007;13:37-52.

10. El-Rafaey H, Templeton A. Induction of abortion in the second trimester by a combination of misoprostol and mifepristone: a randomized comparison between two misoprostol regimens. Hum Reprod. 1995; 10:475-8.

11. Ho PC, Chan YF, Lau W. Misoprostol is as effective as gemeprost in termination of second trimester pregnancy when combined with mifepristone: a randomized comparative trial. Contraception. 1996;53:281-3.

12. Wong KS, Ngai CSW, Yeo ELK, Tang LCH. A comparison of two regimens of intravaginal misoprostol for termination of second trimester pregnancy: a randomized comparative trial. Hum Reprod. 2000;15:709-12.

13. Tang OS, Gemzell, Danielsson K, Ho PC. Misoprostol: pharmacokinetic profiles, effects on uterus and side effects. Int $\mathbf{J}$ Obstet Gynaecol. 2007;99:S160-7.

14. American College of Obstetricians and Gynecologists. Medical management of abortion. In: ACOG, eds. Practice Bulletin No 67. USA: ACOG; October 2005, Reaffirmed 2009.

15. Tang OS, Schweer H, Seyberth NW, Lee SWH, Ho PC. Pharmacokinetics of different routes of administration of misoprostol. Hum Reprod. 2002;17:332-6.

16. Tang OS, Lau WN, Chan CC, Ho PC. A prospective randomized comparison of sublingual versus vaginal Misoprostolin second trimester termination of pregnancy. BJOG. 2004;111:1001-5.

17. Bhattacharjee N, Saha SP, Ghoshroy SC, Bhowmick S, Barui G. Arandomised comparative study on sublingual versus vaginal administration of misoprostol for termination of pregnancy. Aust N Z J Obstet Gynaecol. 2008;48:165-71.

18. Tanha FD, Golquachi T, Niroomand N, Ghajarzadeh M, Nasr R. Sublingual versus vaginal misoprostol for second trimester termination: a randomized clinical trial. Arch Gynaecol Obstet. 2013 Jun;287:65-9.

DOI: $10.5455 / 2320-1770 . i j r \operatorname{cog} 20150423$

Cite this article as: Pandey A, Kundu S, Deshmukh PY. A comparison of intravaginal misoprostol with sublingual misoprostol for second trimester medical termination of pregnancy. Int J Reprod Contracept Obstet Gynecol 2015;4:402-7. 